\title{
Research Article \\ Strong Convergence of Two Iterative Algorithms for Nonexpansive Mappings in Hilbert Spaces
}

\author{
Yonghong Yao, ${ }^{1}$ Yeong Cheng Liou, ${ }^{2}$ and Giuseppe Marino ${ }^{3}$ \\ ${ }^{1}$ Department of Mathematics, Tianjin Polytechnic University, Tianjin 300160, China \\ ${ }^{2}$ Department of Information Management, Cheng Shiu University, Kaohsiung 833, Taiwan \\ ${ }^{3}$ Dipartimento di Matematica, Universitá della Calabria, 87036 Arcavacata di Rende (CS), Italy \\ Correspondence should be addressed to Yonghong Yao, yaoyonghong@yahoo.cn
}

Received 6 April 2009; Accepted 12 September 2009

Recommended by Simeon Reich

We introduce two iterative algorithms for nonexpansive mappings in Hilbert spaces. We prove that the proposed algorithms strongly converge to a fixed point of a nonexpansive mapping $T$.

Copyright (C) 2009 Yonghong Yao et al. This is an open access article distributed under the Creative Commons Attribution License, which permits unrestricted use, distribution, and reproduction in any medium, provided the original work is properly cited.

\section{Introduction}

Let $C$ be a nonempty closed convex subset of a real Hilbert space $H$. Recall that a mapping $T: C \rightarrow C$ is said to be nonexpansive if

$$
\|T x-T y\| \leq\|x-y\|
$$

for all $x, y \in C$. We use Fix $(T)$ to denote the set of fixed points of $T$.

Construction of fixed points of nonlinear mappings is an important and active research area. In particular, iterative algorithms for finding fixed points of nonexpansive mappings have received vast investigation (cf. [1, 2]) since these algorithms find applications in a variety of applied areas of inverse problem, partial differential equations, image recovery, and signal processing see; [3-8]. Iterative methods for nonexpansive mappings have been extensively investigated in the literature; see [1-7, 9-21].

It is our purpose in this paper to introduce two iterative algorithms for nonexpansive mappings in Hilbert spaces. We prove that the proposed algorithms strongly converge to a fixed point of nonexpansive mapping $T$. 


\section{Preliminaries}

Let $C$ be a nonempty closed convex subset of $H$. For every point $x \in H$, there exists a unique nearest point in $C$, denoted by $P_{C} x$ such that

$$
\left\|x-P_{C} x\right\| \leq\|x-y\|, \quad \forall y \in C
$$

The mapping $P_{C}$ is called the metric projection of $H$ onto $C$. It is well known that $P_{C}$ is a nonexpansive mapping.

In order to prove our main results, we need the following well-known lemmas.

Lemma 2.1 (see [22], Demiclosed principle). Let C be a nonempty closed convex of a real Hilbert space $H$. Let $T: C \rightarrow C$ be a nonexpansive mapping. Then $I-T$ is demiclosed at 0 , that is, if $x_{n} \rightarrow x \in C$ and $x_{n}-T x_{n} \rightarrow 0$, then $x=T x$.

Lemma 2.2 (see [20]). Let $\left\{x_{n}\right\},\left\{z_{n}\right\}$ be bounded sequences in a Banach space $E$, and let $\left\{\beta_{n}\right\}$ be a sequence in $[0,1]$ which satisfies the following condition: $0<\liminf _{n \rightarrow \infty} \beta_{n} \leq \limsup _{n \rightarrow \infty} \beta_{n}<1$. Suppose that $x_{n+1}=\left(1-\beta_{n}\right) x_{n}+\beta_{n} z_{n}$ for all $n \geq 0$ and $\lim \sup _{n \rightarrow \infty}\left(\left\|z_{n+1}-z_{n}\right\|-\left\|x_{n+1}-x_{n}\right\|\right) \leq 0$, then $\lim _{n \rightarrow \infty}\left\|z_{n}-x_{n}\right\|=0$.

Lemma 2.3 (see [22]). Assume, that $\left\{a_{n}\right\}$ is a sequence of nonnegative real numbers such that $a_{n+1} \leq$ $\left(1-\gamma_{n}\right) a_{n}+\gamma_{n} \delta_{n}, n \geq 0$, where $\left\{\gamma_{n}\right\}$ is a sequence in $(0,1)$ and $\left\{\delta_{n}\right\}$ is a sequence in $R$ such that

(i) $\sum_{n=0}^{\infty} \gamma_{n}=\infty$,

(ii) $\lim \sup _{n \rightarrow \infty} \delta_{n} \leq 0$ or $\sum_{n=0}^{\infty}\left|\delta_{n} \gamma_{n}\right|<\infty$,

then $\lim _{n \rightarrow \infty} a_{n}=0$.

\section{Main Results}

Let $C$ be a nonempty closed convex subset of a real Hilbert space $H$. Let $T: C \rightarrow C$ be a nonexpansive mapping. For each $t \in(0,1)$, we consider the following mapping $T_{t}$ given by

$$
T_{t} x=T P_{C}[(1-t) x], \quad \forall x \in C .
$$

It is easy to check that $\left\|T_{t} x-T_{t} y\right\| \leq(1-t)\|x-y\|$ which implies that $T_{t}$ is a contraction. Using the Banach contraction principle, there exists a unique fixed point $x_{t}$ of $T_{t}$ in $C$, that is,

$$
x_{t}=T P_{C}\left[(1-t) x_{t}\right]
$$

Theorem 3.1. Let $C$ be a nonempty closed convex subset of a real Hilbert space $H$. Let $T: C \rightarrow C$ be a nonexpansive mapping with $\operatorname{Fix}(T) \neq \emptyset$. For each $t \in(0,1)$, let the net $\left\{x_{t}\right\}$ be generated by (3.2). Then, as $t \rightarrow 0$, the net $\left\{x_{t}\right\}$ converges strongly to a fixed point of $T$.

Proof. First, we prove that $\left\{x_{t}\right\}$ is bounded. Take $u \in \operatorname{Fix}(T)$. From (3.2), we have

$$
\left\|x_{t}-u\right\|=\left\|T P_{C}\left[(1-t) x_{t}\right]-T P_{C} u\right\| \leq(1-t)\left\|x_{t}-u\right\|+t\|u\|,
$$


that is,

$$
\left\|x_{t}-u\right\| \leq\|u\|
$$

Hence, $\left\{x_{t}\right\}$ is bounded.

Again from (3.2), we obtain

$$
\left\|x_{t}-T x_{t}\right\|=\left\|T P_{C}\left[(1-t) x_{t}\right]-T P_{C} x_{t}\right\| \leq t\left\|x_{t}\right\| \longrightarrow 0, \quad \text { as } t \longrightarrow 0 .
$$

Next we show that $\left\{x_{t}\right\}$ is relatively norm compact as $t \rightarrow 0$. Let $\left\{t_{n}\right\} \subset(0,1)$ be a sequence such that $t_{n} \rightarrow 0$ as $n \rightarrow \infty$. Put $x_{n}:=x_{t_{n}}$. From (3.5), we have

$$
\left\|x_{n}-T x_{n}\right\| \longrightarrow 0
$$

From (3.2), we get, for $u \in \operatorname{Fix}(T)$,

$$
\begin{aligned}
\left\|x_{t}-u\right\|^{2} & =\left\|T P_{C}\left[(1-t) x_{t}\right]-T u\right\|^{2} \\
& \leq\left\|x_{t}-u-t x_{t}\right\|^{2} \\
& =\left\|x_{t}-u\right\|^{2}-2 t\left\langle x_{t}, x_{t}-u\right\rangle+t^{2}\left\|x_{t}\right\|^{2} \\
& =\left\|x_{t}-u\right\|^{2}-2 t\left\langle x_{t}-u, x_{t}-u\right\rangle-2 t\left\langle u, x_{t}-u\right\rangle+t^{2}\left\|x_{t}\right\|^{2} .
\end{aligned}
$$

Hence,

$$
\left\|x_{t}-u\right\|^{2} \leq\left\langle u, u-x_{t}\right\rangle+\frac{t}{2}\left\|x_{t}\right\|^{2} \leq\left\langle u, u-x_{t}\right\rangle+\frac{t}{2} M
$$

where $M>0$ is a constant such that $\sup _{t}\left\{\left\|x_{t}\right\|\right\} \leq M$. In particular,

$$
\left\|x_{n}-u\right\|^{2} \leq\left\langle u, u-x_{n}\right\rangle+\frac{t_{n}}{2} M, \quad u \in \operatorname{Fix}(T) .
$$

Since $\left\{x_{n}\right\}$ is bounded, without loss of generality, we may assume that $\left\{x_{n}\right\}$ converges weakly to a point $x^{*} \in C$. Noticing (3.6) we can use Lemma 2.1 to get $x^{*} \in \operatorname{Fix}(T)$. Therefore we can substitute $x^{*}$ for $u$ in (3.9) to get

$$
\left\|x_{n}-x^{*}\right\|^{2} \leq\left\langle x^{*}, x^{*}-x_{n}\right\rangle+\frac{t_{n}}{2} M .
$$

Hence, the weak convergence of $\left\{x_{n}\right\}$ to $x^{*}$ actually implies that $x_{n} \rightarrow x^{*}$ strongly. This has proved the relative norm compactness of the net $\left\{x_{t}\right\}$ as $t \rightarrow 0$.

To show that the entire net $\left\{x_{t}\right\}$ converges to $x^{*}$, assume $x_{t_{m}} \rightarrow \tilde{x} \in \operatorname{Fix}(T)$, where $t_{m} \rightarrow 0$. Put $x_{m}=x_{t_{m}}$. Similarly we have

$$
\left\|x_{m}-x^{*}\right\|^{2} \leq\left\langle x^{*}, x^{*}-x_{m}\right\rangle+\frac{t_{m}}{2} M
$$


Therefore,

$$
\left\|\tilde{x}-x^{*}\right\|^{2} \leq\left\langle x^{*}, x^{*}-\tilde{x}\right\rangle .
$$

Interchange $x^{*}$ and $\tilde{x}$ to obtain

$$
\left\|x^{*}-\tilde{x}\right\|^{2} \leq\left\langle\tilde{x}, \tilde{x}-x^{*}\right\rangle
$$

Adding up (3.12) and (3.13) yields

$$
2\left\|x^{*}-\tilde{x}\right\|^{2} \leq\left\|x^{*}-\tilde{x}\right\|^{2}
$$

which implies that $\tilde{x}=x^{*}$. This completes the proof.

Theorem 3.2. Let $C$ be a nonempty closed convex subset of a real Hilbert space $H$. Let $T: C \rightarrow C$ be a nonexpansive mapping such that $\operatorname{Fix}(T) \neq \emptyset$. Let $\left\{\alpha_{n}\right\}$ and $\left\{\beta_{n}\right\}$ be two real sequences in $(0,1)$. For given $x_{0} \in C$ arbitrarily, let the sequence $\left\{x_{n}\right\}, n \geq 0$, be generated iteratively by

$$
y_{n}=P_{C}\left[\left(1-\alpha_{n}\right) x_{n}\right], \quad x_{n+1}=\left(1-\beta_{n}\right) x_{n}+\beta_{n} T y_{n}
$$

Suppose that the following conditions are satisfied:

(i) $\lim _{n \rightarrow \infty} \alpha_{n}=0$ and $\sum_{n=0}^{\infty} \alpha_{n}=\infty$,

(ii) $0<\liminf _{n \rightarrow \infty} \beta_{n} \leq \lim \sup _{n \rightarrow \infty} \beta_{n}<1$,

then the sequence $\left\{x_{n}\right\}$ generated by (3.15) strongly converges to a fixed point of $T$.

Proof. First, we prove that the sequence $\left\{x_{n}\right\}$ is bounded. Take $u \in \operatorname{Fix}(T)$. From (3.15), we have

$$
\begin{aligned}
\left\|x_{n+1}-u\right\| & =\left\|\left(1-\beta_{n}\right)\left(x_{n}-u\right)+\beta_{n}\left(T y_{n}-u\right)\right\| \\
& \leq\left(1-\beta_{n}\right)\left\|x_{n}-u\right\|+\beta_{n}\left\|y_{n}-u\right\| \\
& \leq\left(1-\beta_{n}\right)\left\|x_{n}-u\right\|+\beta_{n}\left[\left(1-\alpha_{n}\right)\left\|x_{n}-u\right\|+\alpha_{n}\|u\|\right] \\
& =\left(1-\alpha_{n} \beta_{n}\right)\left\|x_{n}-u\right\|+\alpha_{n} \beta_{n}\|u\| \\
& \leq \max \left\{\left\|x_{n}-u\right\|,\|u\|\right\} .
\end{aligned}
$$

Hence, $\left\{x_{n}\right\}$ is bounded and so is $\left\{T x_{n}\right\}$.

Set $z_{n}=T y_{n}, n \geq 0$. It follows that

$$
\begin{aligned}
\left\|z_{n+1}-z_{n}\right\| & =\left\|T y_{n+1}-T y_{n}\right\| \\
& \leq\left\|y_{n+1}-y_{n}\right\| \\
& \leq\left\|\left(1-\alpha_{n+1}\right) x_{n+1}-\left(1-\alpha_{n}\right) x_{n}\right\| \\
& \leq\left\|x_{n+1}-x_{n}\right\|+\alpha_{n+1}\left\|x_{n+1}\right\|+\alpha_{n}\left\|x_{n}\right\| .
\end{aligned}
$$


Hence,

$$
\limsup _{n \rightarrow \infty}\left(\left\|z_{n+1}-z_{n}\right\|-\left\|x_{n+1}-x_{n}\right\|\right) \leq 0 .
$$

This together with Lemma 2.2 implies that

$$
\lim _{n \rightarrow \infty}\left\|z_{n}-x_{n}\right\|=0
$$

Therefore,

$$
\lim _{n \rightarrow \infty}\left\|x_{n+1}-x_{n}\right\|=\lim _{n \rightarrow \infty} \beta_{n}\left\|x_{n}-z_{n}\right\|=0 .
$$

We observe that

$$
\begin{aligned}
\left\|x_{n}-T x_{n}\right\| & \leq\left\|x_{n}-x_{n+1}\right\|+\left\|x_{n+1}-T x_{n}\right\| \\
& \leq\left\|x_{n}-x_{n+1}\right\|+\left(1-\beta_{n}\right)\left\|x_{n}-T x_{n}\right\|+\beta_{n}\left\|T y_{n}-T x_{n}\right\| \\
& \leq\left\|x_{n}-x_{n+1}\right\|+\left(1-\beta_{n}\right)\left\|x_{n}-T x_{n}\right\|+\beta_{n}\left\|y_{n}-x_{n}\right\| \\
& \leq\left\|x_{n}-x_{n+1}\right\|+\left(1-\beta_{n}\right)\left\|x_{n}-T x_{n}\right\|+\alpha_{n}\left\|x_{n}\right\|,
\end{aligned}
$$

that is,

$$
\left\|x_{n}-T x_{n}\right\| \leq \frac{1}{\beta_{n}}\left\{\left\|x_{n+1}-x_{n}\right\|+\alpha_{n}\left\|x_{n}\right\|\right\} \longrightarrow 0
$$

Let the net $\left\{x_{t}\right\}$ be defined by (3.2). By Theorem 3.1, we have $x_{t} \rightarrow x^{*}$ as $t \rightarrow 0$. Next we prove $\lim \sup _{n \rightarrow \infty}\left\langle x^{*}, x^{*}-x_{n}\right\rangle \leq 0$. Indeed,

$$
\begin{aligned}
\left\|x_{t}-x_{n}\right\|^{2} & =\left\|x_{t}-T x_{n}+T x_{n}-x_{n}\right\|^{2} \\
& =\left\|x_{t}-T x_{n}\right\|^{2}+2\left\langle x_{t}-T x_{n}, T x_{n}-x_{n}\right\rangle+\left\|T x_{n}-x_{n}\right\|^{2} \\
& \leq\left\|x_{t}-T x_{n}\right\|^{2}+M\left\|x_{n}-T x_{n}\right\| \\
& \leq\left\|(1-t) x_{t}-x_{n}\right\|^{2}+M\left\|x_{n}-T x_{n}\right\| \\
& =\left\|x_{t}-x_{n}\right\|^{2}-2 t\left\langle x_{t}, x_{t}-x_{n}\right\rangle+t^{2}\left\|x_{t}\right\|^{2}+M\left\|x_{n}-T x_{n}\right\| \\
& \leq\left\|x_{t}-x_{n}\right\|^{2}-2 t\left\langle x_{t}, x_{t}-x_{n}\right\rangle+t^{2} M+M\left\|x_{n}-T x_{n}\right\|,
\end{aligned}
$$

where $M>0$ such that $\sup \left\{\left\|x_{t}\right\|^{2}, 2\left\|x_{t}-T x_{n}\right\|,\left\|x_{t}-x_{n}\right\|, t \in(0,1), n \geq 0\right\} \leq M$. It follows that

$$
\left\langle x_{t}, x_{t}-x_{n}\right\rangle \leq \frac{t}{2} M+\frac{M}{2 t}\left\|T x_{n}-x_{n}\right\| .
$$


Therefore,

$$
\limsup _{t \rightarrow 0} \limsup _{n \rightarrow \infty}\left\langle x_{t}, x_{t}-x_{n}\right\rangle \leq 0
$$

We note that

$$
\begin{aligned}
\left\langle x^{*}, x^{*}-x_{n}\right\rangle & =\left\langle x^{*}, x^{*}-x_{t}\right\rangle+\left\langle x^{*}-x_{t}, x_{t}-x_{n}\right\rangle+\left\langle x_{t}, x_{t}-x_{n}\right\rangle \\
& \leq\left\langle x^{*}, x^{*}-x_{t}\right\rangle+\left\|x^{*}-x_{t}\right\|\left\|x_{t}-x_{n}\right\|+\left\langle x_{t}, x_{t}-x_{n}\right\rangle \\
& \leq\left\langle x^{*}, x^{*}-x_{t}\right\rangle+\left\|x^{*}-x_{t}\right\| M+\left\langle x_{t}, x_{t}-x_{n}\right\rangle .
\end{aligned}
$$

This together with $x_{t} \rightarrow x^{*}$ and (3.25) implies that

$$
\limsup _{n \rightarrow \infty}\left\langle x^{*}, x^{*}-x_{n}\right\rangle \leq 0
$$

Finally we show that $x_{n} \rightarrow x^{*}$. From (3.15), we have

$$
\begin{aligned}
\left\|x_{n+1}-x^{*}\right\|^{2} & \leq\left(1-\beta_{n}\right)\left\|x_{n}-x^{*}\right\|^{2}+\beta_{n}\left\|y_{n}-x^{*}\right\|^{2} \\
& \leq\left(1-\beta_{n}\right)\left\|x_{n}-x^{*}\right\|^{2}+\beta_{n}\left\|\left(1-\alpha_{n}\right)\left(x_{n}-x^{*}\right)-\alpha_{n} x^{*}\right\|^{2} \\
& \leq\left(1-\beta_{n}\right)\left\|x_{n}-x^{*}\right\|^{2}+\beta_{n}\left[\left(1-\alpha_{n}\right)\left\|x_{n}-x^{*}\right\|^{2}-2 \alpha_{n}\left(1-\alpha_{n}\right)\left\langle x^{*}, x_{n}-x^{*}\right\rangle+\alpha_{n}^{2}\left\|x^{*}\right\|^{2}\right] \\
& \leq\left(1-\alpha_{n} \beta_{n}\right)\left\|x_{n}-x^{*}\right\|^{2}+\alpha_{n} \beta_{n}\left[2\left(1-\alpha_{n}\right)\left\langle x^{*}, x^{*}-x_{n}\right\rangle+\frac{\alpha_{n}}{\beta_{n}}\left\|x^{*}\right\|^{2}\right] .
\end{aligned}
$$

We can check that all assumptions of Lemma 2.3 are satisfied. Therefore, $x_{n} \rightarrow x^{*}$. This completes the proof.

\section{Acknowledgment}

The second author was partially supposed by the Grant NSC 98-2622-E-230-006-CC3 and NSC 98-2923-E-110-003-MY3.

\section{References}

[1] K. Goebel and S. Reich, Uniform Convexity, Hyperbolic Geometry, and Nonexpansive Mappings, vol. 83 of Monographs and Textbooks in Pure and Applied Mathematics, Marcel Dekker, New York, NY, USA, 1984.

[2] S. Reich, "Almost convergence and nonlinear ergodic theorems," Journal of Approximation Theory, vol. 24, no. 4, pp. 269-272, 1978.

[3] C. Byrne, "A unified treatment of some iterative algorithms in signal processing and image reconstruction," Inverse Problems, vol. 20, no. 1, pp. 103-120, 2004.

[4] P. L. Combettes, "On the numerical robustness of the parallel projection method in signal synthesis," IEEE Signal Processing Letters, vol. 8, no. 2, pp. 45-47, 2001. 
[5] P. L. Combettes, "The convex feasibility problem in image recovery," in Advances in Imaging and Electron Physics, P. Hawkes, Ed., vol. 95, pp. 155-270, Academic Press, New York, NY, USA, 1996.

[6] H. W. Engl and A. Leitão, "A Mann iterative regularization method for elliptic Cauchy problems," Numerical Functional Analysis and Optimization, vol. 22, no. 7-8, pp. 861-884, 2001.

[7] C. I. Podilchuk and R. J. Mammone, "Image recovery by convex projections using a least-squares constraint," Journal of the Optical Society of America, vol. 7, no. 3, pp. 517-512, 1990.

[8] D. Youla, "Mathematical theory of image restoration by the method of convex projection," in Image Recovery Theory and Applications, H. Stark, Ed., pp. 29-77, Academic Press, Orlando, Fla, USA, 1987.

[9] H. H. Bauschke, "The approximation of fixed points of compositions of nonexpansive mappings in Hilbert space," Journal of Mathematical Analysis and Applications, vol. 202, no. 1, pp. 150-159, 1996.

[10] F. E. Browder and W. V. Petryshyn, "Construction of fixed points of nonlinear mappings in Hilbert space," Journal of Mathematical Analysis and Applications, vol. 20, pp. 197-228, 1967.

[11] B. Halpern, "Fixed points of nonexpanding maps," Bulletin of the American Mathematical Society, vol. 73, pp. 957-961, 1967.

[12] J. S. Jung, "Viscosity approximation methods for a family of finite nonexpansive mappings in Banach spaces," Nonlinear Analysis: Theory, Methods \& Applications, vol. 64, no. 11, pp. 2536-2552, 2006.

[13] T.-H. Kim and H.-K. Xu, "Robustness of Mann's algorithm for nonexpansive mappings," Journal of Mathematical Analysis and Applications, vol. 327, no. 2, pp. 1105-1115, 2007.

[14] P.-L. Lions, "Approximation de points fixes de contractions," Comptes Rendus de l'Académie des Sciences. Série I. Mathématique, vol. 284, no. 21, pp. A1357-A1359, 1977.

[15] A. Moudafi, "Viscosity approximation methods for fixed-points problems," Journal of Mathematical Analysis and Applications, vol. 241, no. 1, pp. 46-55, 2000.

[16] S. Reich, "Weak convergence theorems for nonexpansive mappings in Banach spaces," Journal of Mathematical Analysis and Applications, vol. 67, no. 2, pp. 274-276, 1979.

[17] S. Reich, "Strong convergence theorems for resolvents of accretive operators in Banach spaces," Journal of Mathematical Analysis and Applications, vol. 75, no. 1, pp. 287-292, 1980.

[18] N. Shioji and W. Takahashi, "Strong convergence of approximated sequences for nonexpansive mappings in Banach spaces," Proceedings of the American Mathematical Society, vol. 125, no. 12, pp. 3641-3645, 1997.

[19] T. Suzuki, "Strong convergence theorems for infinite families of nonexpansive mappings in general Banach spaces," Fixed Point Theory and Applications, vol. 2005, no. 1, pp. 103-123, 2005.

[20] T. Suzuki, "Strong convergence of approximated sequences for nonexpansive mappings in Banach spaces," Proceedings of the American Mathematical Society, vol. 135, pp. 99-106, 2007.

[21] R. Wittmann, "Approximation of fixed points of nonexpansive mappings," Archiv der Mathematik, vol. 58, no. 5, pp. 486-491, 1992.

[22] H.-K. Xu, "Viscosity approximation methods for nonexpansive mappings," Journal of Mathematical Analysis and Applications, vol. 298, no. 1, pp. 279-291, 2004. 